\title{
Performance and Emission Analysis of Single Cylinder Diesel Engine under the influence of Magnetic Fuel Energizer
}

\author{
Piyush M Patel ${ }^{1}$, Gaurav P Rathod ${ }^{2}$, Tushar M Patel ${ }^{3}$ \\ ${ }^{\prime}$ (ME Scholar, Department of Mechanical Engineering, Gujarat, India) \\ ${ }^{2}$ (Assistant Professor, Department of Mechanical Engineering, Gujarat, India) \\ ${ }_{3}^{3}$ (Associate Professor, Department of Mechanical Engineering, Gujarat, India)
}

\begin{abstract}
The present study about the experimental investigates on the Performance and Emission of Single Cylinder Four Stroke Diesel engine under the influence of magnetic field. The influence of magnetic field on the engine performance parameters such as specific fuel consumption, break thermal efficiency, exhausts emissions etc. by applying the magnetic field along the fuel line immediately before fuel injector. The strong permanent magnet of strength 9000 gauss is applied to fuel line for magnetic field. At different engine load conditions the experiments are conducted. An exhaust gas analyzer is used to measure the exhaust gas emissions such as CO, $\mathrm{CO}_{2}, \mathrm{HC}$ and $\mathrm{NO}_{X}$. With the application of magnetic field the percentage reduction in fuel consumption is about $8 \%$ at higher load, the percentage reduction in $\mathrm{HC}$ and $\mathrm{NO}_{X}$ is about $32 \%$ and $27 \%$ respectively. The CO emission gets reduced with the application of magnetic field at higher load. The percentage reduction in $\mathrm{CO}_{2}$ emissions is reduced about $11 \%$ at average of all loads with the effect of magnetic field.
\end{abstract}

Keywords: Efficiency, Emission, Exhaust gas analyzer, Magnetic Fuel Energizer.

\section{INTRODUCTION}

In India, the use of vehicles increases in huge amount over the last decades. In internal combustion engine, generally fuels are use in the form of liquid and they do not combust until they are vaporized and mixed with air. In internal combustion engine, decrease in efficiency, clogs stalling, and loss of horsepower due to fossil fuels that leave a natural deposit of carbon residue[4].

Generally a fuel for internal combustion engine is compound of number of molecules. Each and every molecule consists of a number of atoms made up of number of nucleus and electrons, which orbit their nucleus. Molecules of fuel have not been realigned; so that fuel is not actively interlocked with oxygen during combustion. Molecules have positive and negative electrical charges. Magnets are the prime source that control of the position of electrons. For example, a magnetic coil controls the sweep of our television's electron gun [5]. Therefore, magnets change the orientation of electron in orbit and molecules of fuel have been realigned and ionized.

In vehicles mostly diesel engines have been widely used which lead to lower efficiency and produce tremendous amount of pollutants such as $\mathrm{CO}, \mathrm{HC}, \mathrm{NO}_{\mathrm{X}}, \mathrm{CO}_{2}$ etc due to incomplete combustion of fossil fuel. There are so many different methods (MPFI, EGR, PCV, catalytic) used for improve the performance but to tackle this problem easiest way is use of MAGNETIC FUEL ENERGIZER.

\section{Magnetic Fuel Energizer}

Hydrogen occurs in two distinct isomeric forms one is para which is normally occurs in fuels, second is ortho which achieved by applying magnetic field. These two forms are characterized by the different opposite nucleus spins. The ortho state can be achieved by applying strong magnetic field along the fuel line [2]. In the para Hydrogen molecule, which occupies the anti-parallel rotation, the spin state of one atom relative to another is in the opposite direction, therefore it is diamagnetic. In the ortho molecule, which occupies the parallel rotational levels, the spin state of one atom relative to another is in the same direction, therefore, it is paramagnetic [3]. 


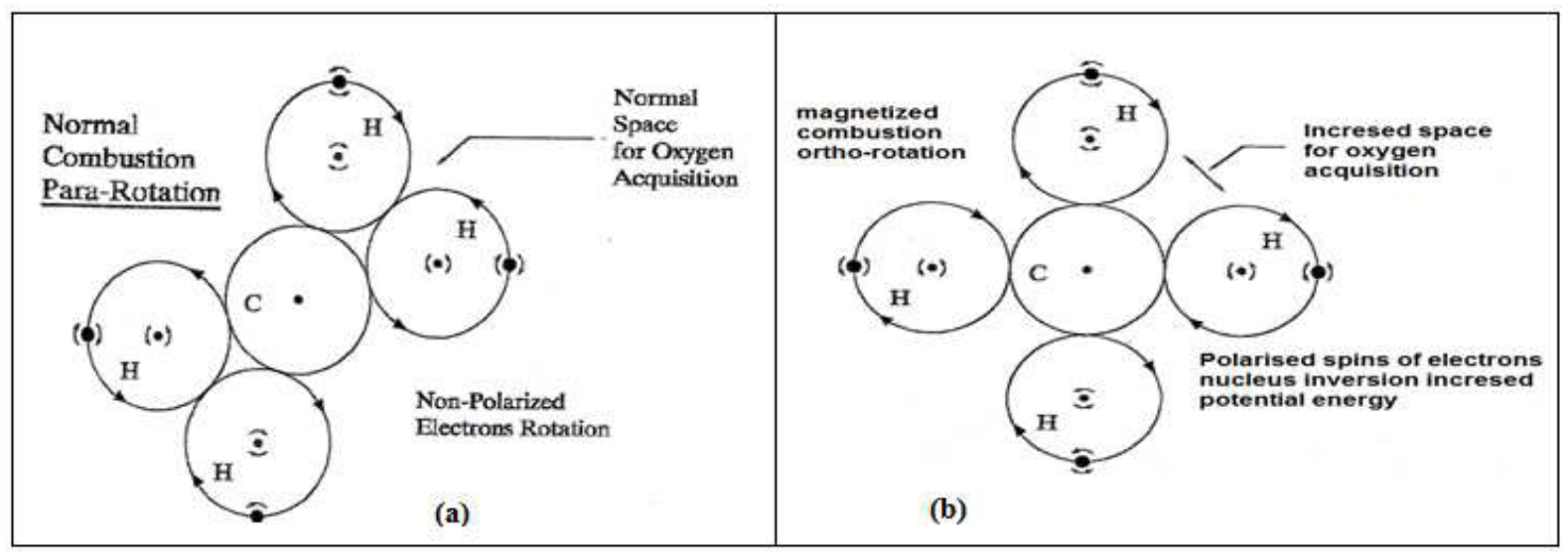

Fig.1 Schematic view of (a) Para state of Hydrogen and (b) Ortho state of Hydrogen [6]

When the fuel passes through a magnetic field, created by the strong permanent magnets, due to that magnetic field hydrocarbon change their orientation and convert from para state to ortho state as shown in Fig.1. In ortho state inter molecular force is considerably reduced and increase space between hydrogen. This hydrogen of fuel actively interlocks with oxygen and producing a more complete burn in the combustion chamber. The magnetic field helps to disperse oil particles and to become finely divided. Figure.1 shows the schematic view of para state and ortho state of Hydrogen of clusters of hydrocarbons changed with the influence of magnetic field and they are more dispersed.

\section{Experimental Set Up And Procedure}

The performance tests were carried out on a single cylinder, four stroke water cooled Diesel engine. The setup consists of an engine, an eddy current dynamometer, and an exhaust gas analyzer.

Table.1 Technical Specifications of Engine

\begin{tabular}{|l|l|}
\hline Model & TV1 \\
\hline Make & Kirlosker Oil Engines \\
\hline Type & Four stroke, Water cooled, Diesel \\
\hline No. of cylinder & One \\
\hline Bore & $87.5 \mathrm{~mm}$ \\
\hline Stroke & $110 \mathrm{~mm}$ \\
\hline Combustion principle & Compression ignition \\
\hline Cubic capacity & 0.661 liters \\
\hline Compression ratio 3 port & $17.5: 1$ \\
\hline Lubrication system & Forced feed system \\
\hline
\end{tabular}

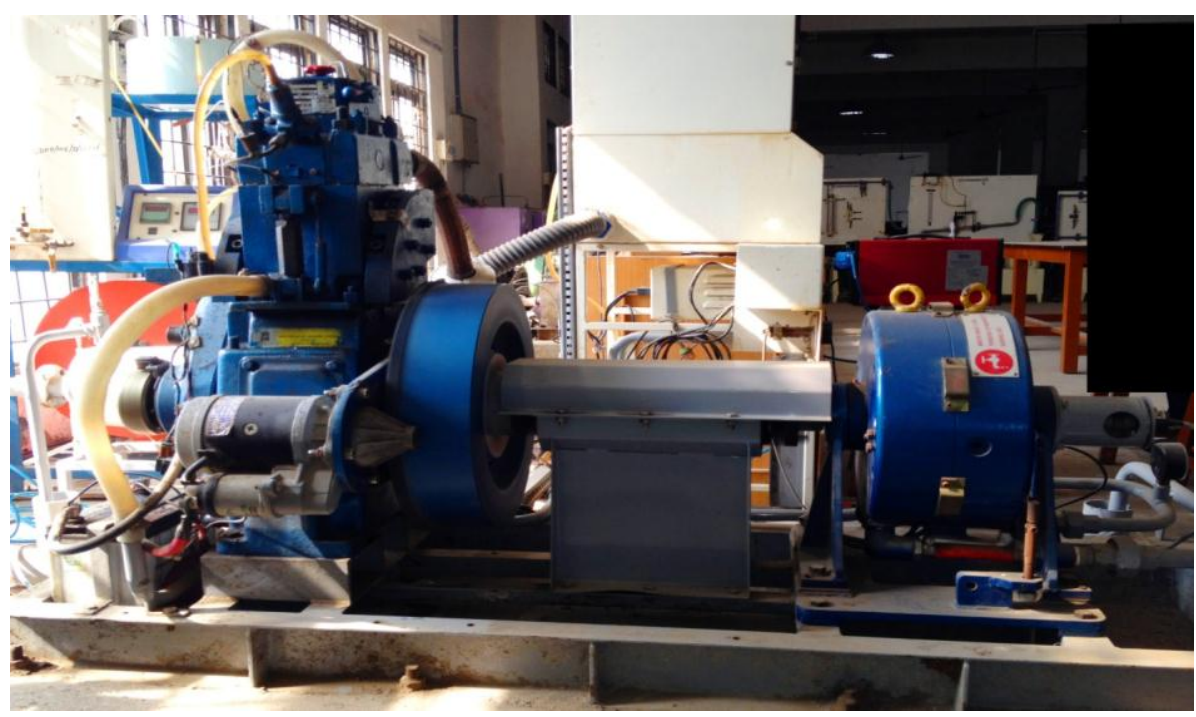

Fig.2 Photographic view of single cylinder four stroke diesel engine 
The engine was prepared to run on diesel as a fuel during all tests as shown in Fig.2. The fuel system is designed to facilitate for accurate measurement of the fuel flow rate. The fuel consumption is measured directly by using the burette method. The fuel consumption was measured at different engine loading conditions and exhaust gas measured by Exhaust gas analyzer. The exhaust gas analyzer is used to measure exhaust emissions from the engine during experimental tests as shown in Fig.3. It is measures gases such as $\mathrm{HC}, \mathrm{CO}, \mathrm{NO}_{\mathrm{X}}$ and $\mathrm{CO}_{2}$ concentrations at each and every load. This procedure was done twice one for without magnet situation and other for with magnet situation, and results were compared.

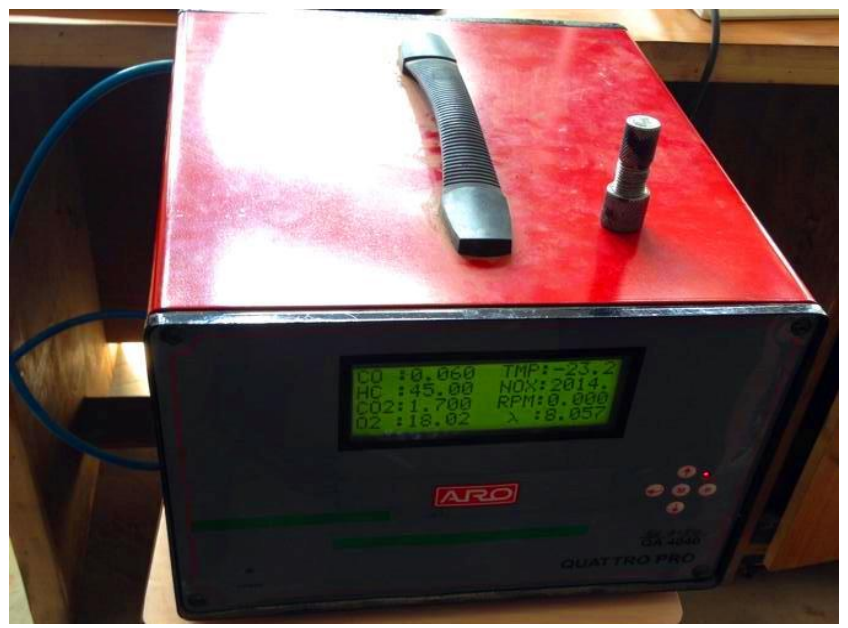

Fig.3. Photographic view of exhaust gas analyzer

Properties of Magnet: Neodymium Magnets also known as Neo magnet which is most widely used type of rare earth magnet and in bright silver colour as shown in Fig.4. This is a permanent magnet which made from alloy of neodymium, iron and boron and this magnet considered to be the strongest magnet type among other permanent magnet. This magnet widely used in electronic based companies and also as motor in cordless tools. The magnetic strength is 9000 gauss.

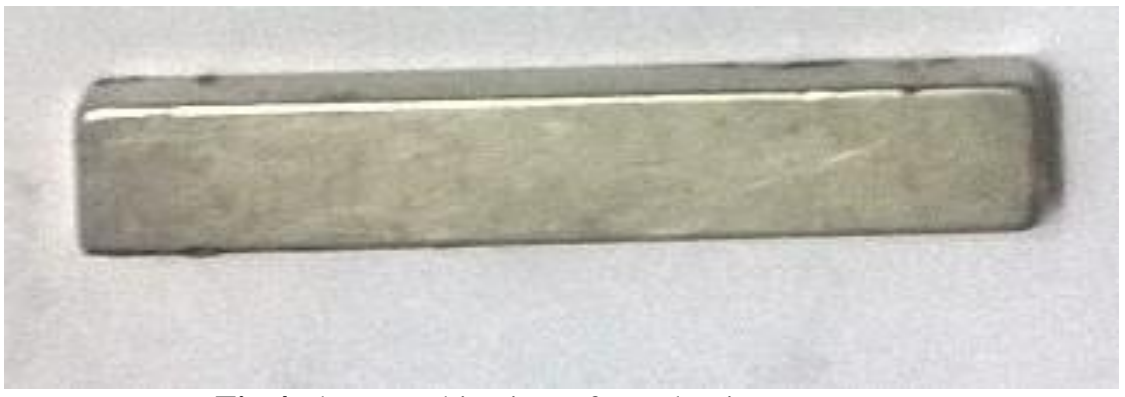

Fig.4 Photographic view of Neodymium Magnets

Installation Position: It is just before the injector on inlet pipe or housing for maximum alignment \& maximum effect.

\section{Magnetic field effect on Specific fuel consumption}

\section{Results And Discussion}

The experimental results show that the fuel consumption of engine was less when the engine with magnet than that without fuel magnet at higher load. Always less amount of fuel was consumed with the fuel with magnetic field. The SFC vs LOAD graph is as shown in fig.5 


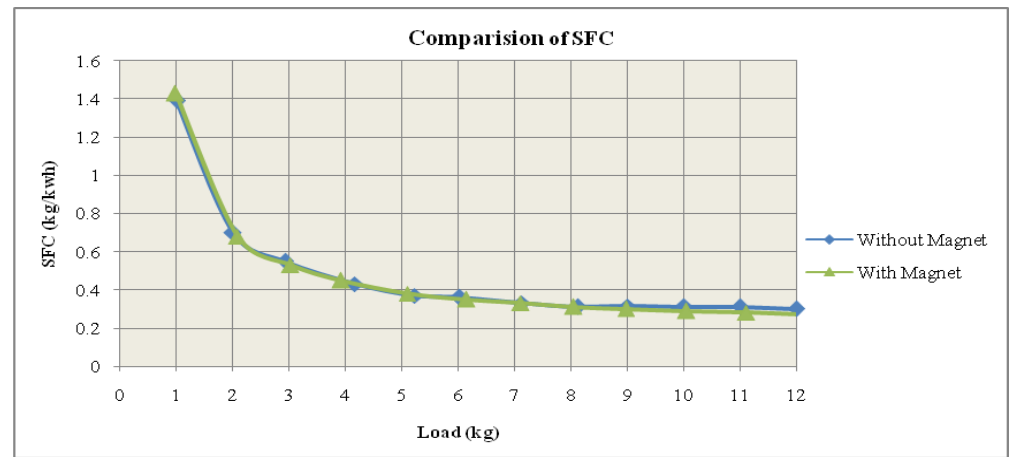

Fig.5 Variation of Specific fuel consumption with load

\section{Magnetic field effect on Brake Thermal Efficiency}

The experimental results show that the Brake Thermal Efficiency of engine was less when the engine with magnet than that without fuel magnet at higher load.

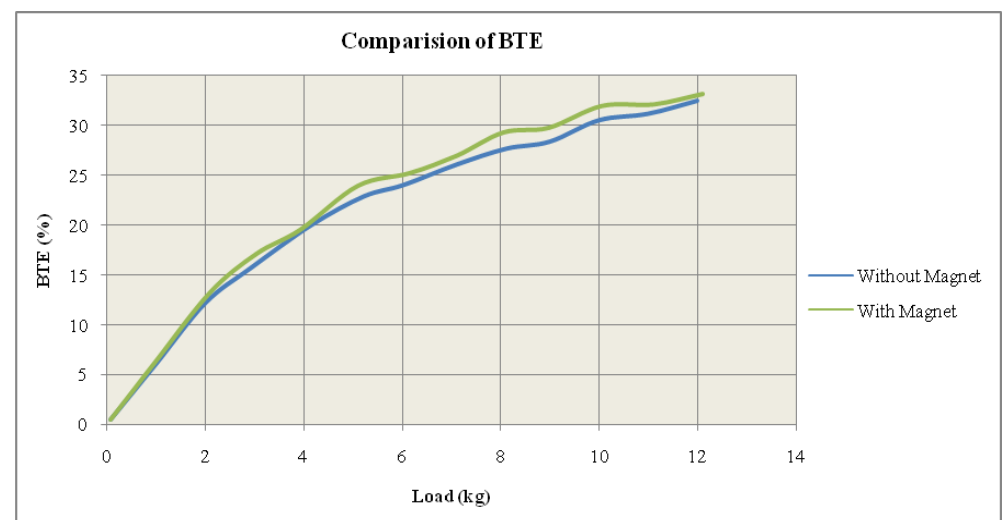

Fig.6 Variation of Brake Thermal Efficiency with load

The variation of Brake power Vs brake thermal efficiency is as shown in fig.6. It is clear that with the application of magnetic field the brake thermal efficiency goes on increasing. The percentage increase of brake thermal efficiency is about up to $4 \%$.

\section{Magnetic field effect on $\mathrm{NO}_{\mathrm{x}}$ emissions}

The $\mathrm{NO}_{\mathrm{X}}$ emission gets decrease with the application of magnetic field as compared to the $\mathrm{NO}_{\mathrm{X}}$ without magnetic field. Here the magnetic field shows adverse effect. The $\mathrm{NO}_{\mathrm{X}}$ emissions are decrease around $27 \%$ at average of all loads. The variation of $\mathrm{NO}_{\mathrm{X}}$ emissions with load is as shown in fig.7

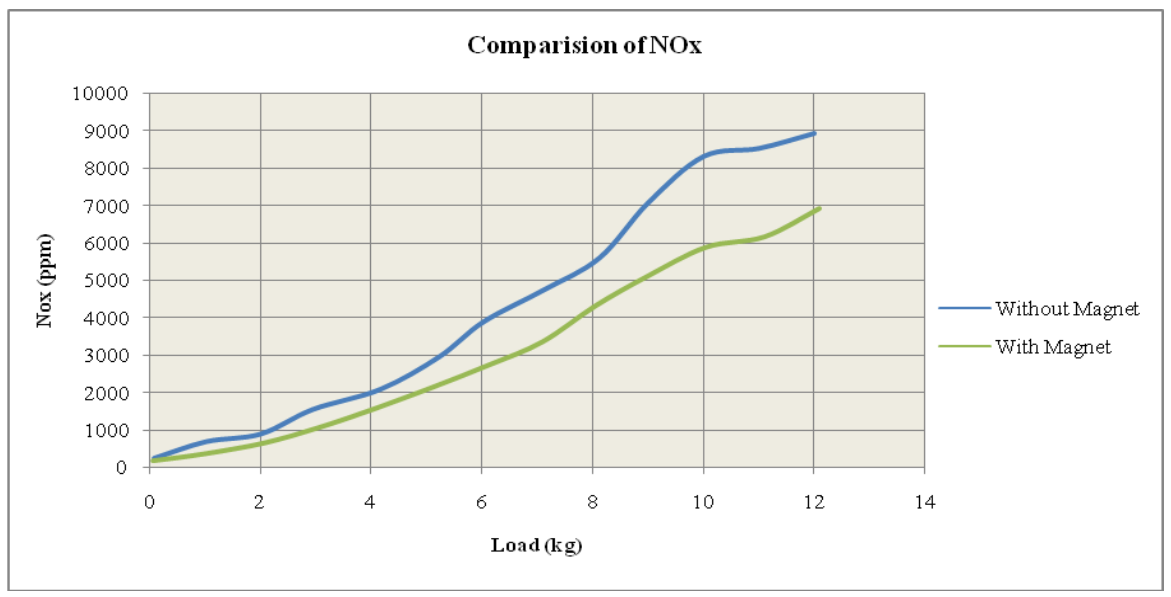

Fig7 Variation of $\mathrm{NO}_{\mathrm{X}}(\mathrm{ppm})$ with load 


\section{Magnetic field effect on HC emissions}

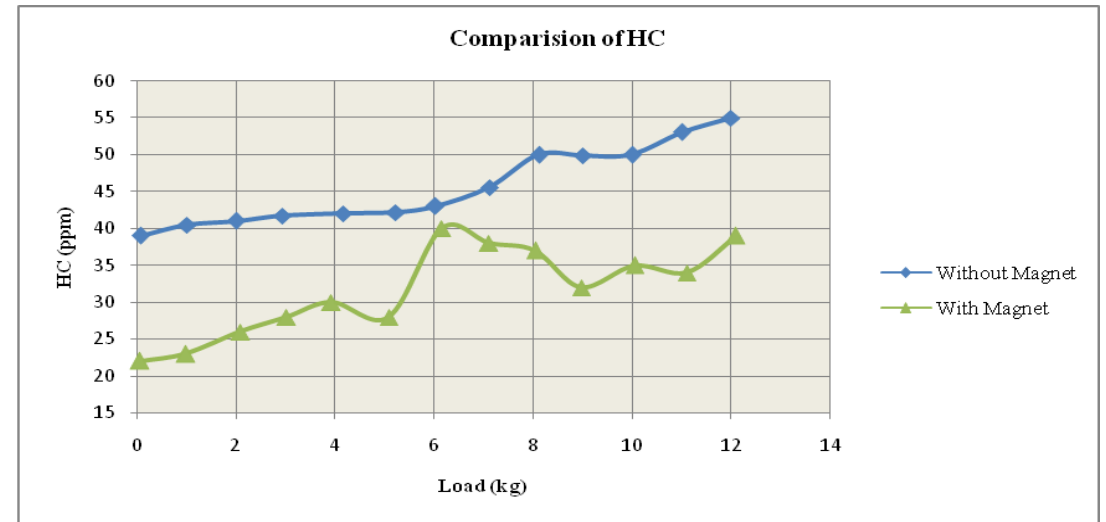

Fig.8 Variation of HC(ppm) with load

Fig.8. Clearly shows the effect of magnetic field on $\mathrm{HC}$ emissions, and the percentage reduction of $\mathrm{HC}$. The HC emissions are decrease around $32 \%$ at average of all loads. The variation of HC emissions with load is as shown in fig.8

\section{Magnetic field effect on CO emissions}

With the application of magnetic field $\mathrm{CO}$ emissions gets reduced as compared to the $\mathrm{CO}$ emissions without magnetic field. Fig.9. Clearly shows the effect of magnetic field on $\mathrm{CO}$ emissions and the $\mathrm{CO}$ emission reduces at higher load.

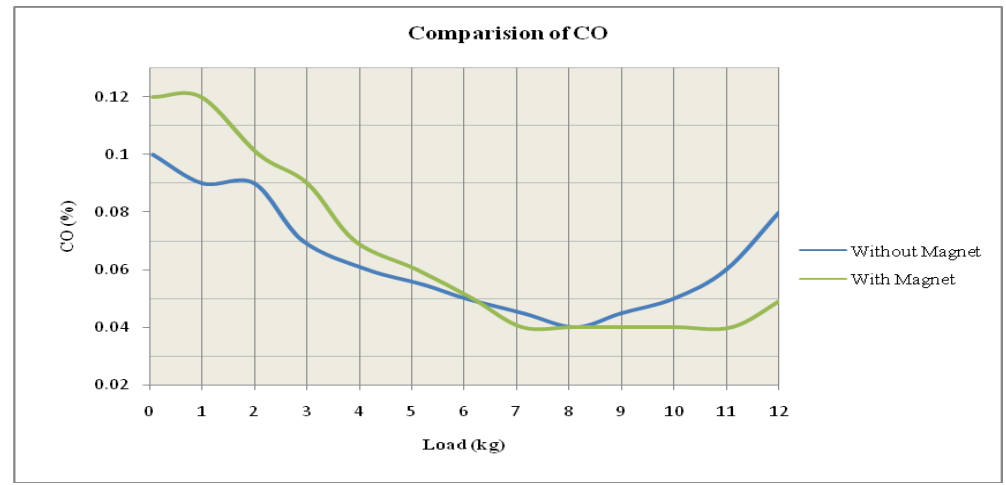

Fig.9 Variation of CO with load

\section{Magnetic field effect on CO2 emissions}

The $\mathrm{CO} 2$ emission gets decrease with the application of magnetic field as compared to the $\mathrm{CO} 2$ without magnetic field. Here the magnetic field shows adverse effect. The $\mathrm{CO} 2$ emissions are decrease around $11 \%$ at average of all loads. The variation of $\mathrm{CO} 2$ emissions with load is as shown in fig. 10

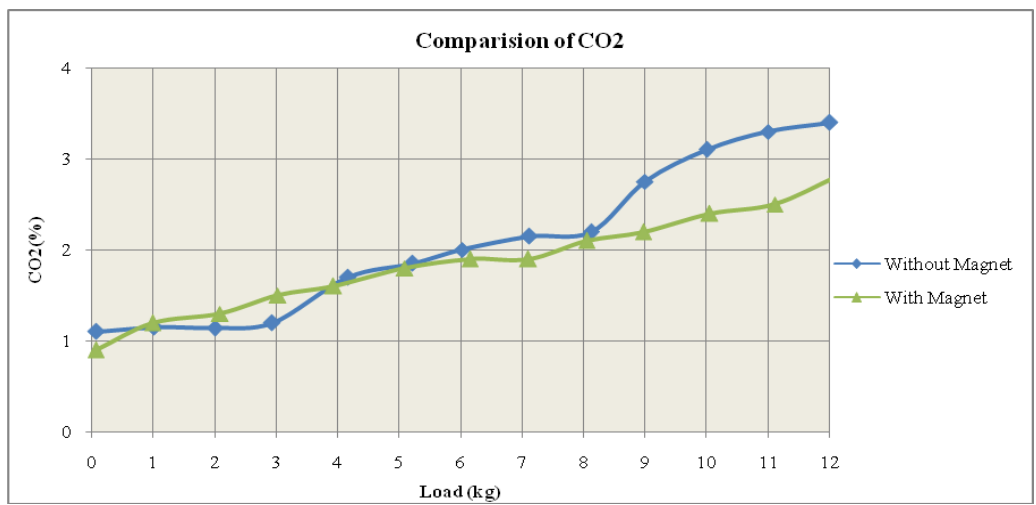

Fig.10 Variation of $\mathrm{CO} 2$ with load 


\section{Conclusion}

From the above experimental results the following conclusions were made:

- It is clear from the experiment result that the brake thermal efficiency increases due to the reduction of fuel consumption at higher load and there is significant reduction in the exhaust emissions at all load condition.

- The experiments results show the magnetic effect on fuel consumption reduction was up to $8 \%$ at higher load condition. The $\mathrm{CO}$ emission gets reduce at higher load. The effect on $\mathrm{NO}_{\mathrm{x}}$ emissions reduces range up to $27 \%$. The reduction of $\mathrm{HC}$ emissions was range up to $32 \%$. The $\mathrm{CO}_{2}$ emission reduction was up to $11 \%$ at average of all loads.

\section{References}

[1] Kevin Kendall *, Maria R. Kosseva, Nanoparticle aggregation influenced by magnetic fields, Colloids and Surfaces A: Physicochem. Eng. Aspects 286 (2006) 112-116

[2] P. Govindasamy and S. Dhandapani,"Experimental Investigation of Cyclic Variation of Combustion Parameters in Catalytically Activated and Magnetically Energized Two-stroke SI Engine”. Journal of scientific and industrial research vol.66, 2007;pp-457-463

[3] Farrag A.El Fatih, 2Gad M.saber, Effect of Fuel Magnetism on Engine Performance and Emissions, Australian Journal of Basic and Applied Sciences, 4(12): 6354-6358, 2010 ISSN 1991-8178

[4] Shweta Jain, Prof. Dr. Suhas Deshmukh,2012 Experimental Investigation of Magnetic Fuel Conditioner (M.F.C) in I.C. engine, ISSN: 2250-3021 Volume 2, Issue 7 (July 2012), PP 27-31

[5] Ali S. Faris, Saadi K. Al-Naseri, Nather Jamal, Raed Isse, Mezher Abed, Zainab Fouad, Akeel Kazim, Nihad Reheem, Ali Chaloob, Hazim Mohammad, Hayder Jasim, Jaafar Sadeq, Ali Salim, Aws Abas, Effects of Magnetic Field on Fuel Consumption and Exhaust, Emissions in Two-Stroke Engine, Energy Procedia 18 ( 2012 ) 327 - 338 www.sciencedirect.com

[6] Vivek Ugare, Nikhil Bhave, Sandeep Lutade,2013 Performance of spark ignition engine under the influence of magnetic field, International journal of research in aeronautical and mechanical engineering, vol.1 Issue.3 July 2013 Pgs:36-43 